only modified the dosage, and he adds his testimony to the great value of the drug.

This method, should nothing supersede it, will thus become almost as valuable as that of quinine in the treatment of malaria. In Koch's words, "Daraus geht doch aber mit aller Bestimmtheit hervor, dass durch eine geeignete Atoxyl behandlung sehr vielen Schlafkranke1. das leben gerettet werden kann."

(4) Destruction of tsetse-flies.-This, so far as we know at present, is not directly practicable, but the flies can be driven away by cutting the jungle. The making of clearings where the natives most frequent, such as at watering places, river fords, and around villages, will certainly be beneficial.

For the present, then, we have at our disposal methods the results of which we shall soon learn. In conclusion, it is, I think, certain that when some of the disputed points indicated above are settled the campaign against the disease will be carried out with greater efficiency because based on more certain knowledge.

J. W. W. S.

\section{WATER VAPOUR IN THE MARTIAN ATMOSPHERE.}

NE of the most telling arguments which has been used against the possibility of the planet Mars being habitable has been that spectroscopists have failed to detect with certainty the presence of water vapour in the planet's atmosphere. It now seems probable that this objection will have to be abandoned, for, in a telegram recently received by Sir Norman Lockyer, Prof. Lowell announces that Mr. Slipher has got on repeated plates-specially prepared for this research - the water vapour bands $a$ and near D stronger in the spectrum of Mars than in that of the moon at the same altitude.

Should Prof. Lowell's further researches confirm it, this result is one of the most important links in the remarkable chain of evidence for a habitable Mars. The photography of the canals was a great step forward, but the presence of these features was unconvincing unless it could be proved that the water to fill them in their proper seasons was available. Similarly, the seasonal increase and decrease in the dimensions of the snow-caps were thought to be conclusive evidence for the presence of water until the frozen carbon dioxide theory was advanced, although this theory left unexplained the ill-defined edges of the disappearing snowfields. But, so far as our present knowledge goes, it is difficult to see how carbon dioxide is able to produce the intensification of the water-vapour bands in the spectrum of the planet's atmosphere.

For many years, in fact since the actual existence of permanent features on the planet's surface was established, this question of water vapour - of the existence of a substance capable of producing clouds and mists-has been one of the chief points of contention among areographers. So far back as $186_{3}$ Sir Norman Lockyer, in a communication to the Royal Astronomical Society (Memoirs, vol. xxxii., p. I79, I863), describing his observations of Mars during the opposition of $\mathrm{x} 862$, stated that " although the complete fixity of the main features of the planet has been thus placed beyond all doubt, daily-nay, hourly-changes in the detail and in the tones of the different parts of the planet, both light and dark, occur. These changes are, I doubt not, caused by the transit of clouds over the different features." The drawings accompanying the memoir illustrated the changes mentioned, and confirmed the suspicions of cloud effects noticed by Secchi in 1858 . But the NO. 2002 , VOL. 77] assumption that these effects were caused by clouds and mists entailed the assumption of the presence of water vapour in the planet's atmosphere, and the spectroscopic evidence for this has hitherto been too indefinite. Suspected by Huggins and Vogel in I867 and 1873 respectively, its presence was negatived by the subsequent spectroscopic researches of Campbell and Keeler, but now it appears certain, from this latest result from the Lowell Observatory, that water vapour is one of the concomitants of the Martian atmosphere.

In his recent book, "Is Mars Habitable?" reviewed by Dr. Lockyer in NATuRE for February I3 (p. 337), Dr. Russel Wallace insisted on the absence of spectroscopic evidence as a strong argument against the presence of water vapour. This objection is now removed, and once more it becomes reasonable to suppose that the Martian surface is, at least to some extent, supplied with that compound which, to terrestrial minds, is one of the essentials of habitability. At the same time, the theories advanced by Prof. Lowell to explain the remarkable variety of appearances and changes from season to season, disclosed by his wonderful observations, have received support worthy of their brilliant conceptions.

William E. Rolston.

\section{NOTES.}

IN an announcement in last week's Nature it was stated that Prof. Kamerlingh Onnes had succeeded in liquefying helium. It should have been stated that the gas was solidified, no intermediate liquid stage being observed. The demonstration was made in the presence of Prof. H. A. Lorentz and Prof. J. P. Kuenen, both of the University of Leyden. The method adopted is described by the Leyden correspondent of the Daily Telegraph (March Io) as follows, and is the same as that used with success by bith Sir James Dewar and Prof. Olszewski. The only noteworthy point is the large amount of helium used for the instantaneous expansion. "To make this experiment," Prof. Onnes says, "I placed a tube with thick sides, containing a thinner one for extra protection against external warming influences, in a vessel filled with liquid hydrogen, at $-434^{\circ} \mathrm{F}$., and in this tube about one and a half gallon of helium was compressed under Ioo atmospheres. On allowing expansion to a lower temperature a cloud appeared, which increased as the expansion in vacuo continued. Out of the nebulous mass a white flocculent substance gathered in the inner tube, wherealthough the tube was well closed-it evaporated within twenty seconds. Some solid substance, however, was left, the pressure in the tube meanwhile rising to one atmosphere, and when the valve was opened and the pressure was reduced this substance exhaled almost immediately, no sign of liquefaction being observable. The substance which remained at a temperature of $-434^{\circ} \mathrm{F}$. was solid helium." We are glad to be able to print the telegraphic message sent to Sir James Dewar by Prof. Onnes on March 5, and Sir James Dewar's reply to it :- Prof. Onnes to Sir James Dewar, Royal Institution, London: "Converted helium into solid. Last evaporating parts show considerable vapour pressures, as if liquid state is jumped over." Sir James Dewar to Prof. Onnes, University, Leyden : "Congratulations. Glad my anticipation of the possibility of the achievement by known methods confirmed. My helium work arrested by ill-health, but hope to continue later on."

The council of the British Association has nominated Prof. J. J. Thomson, F.R.S., as president of the association for the meeting to be held next year in Winnipeg, 